УДК 547.972

\title{
ИССЛЕДОВАНИЕ НЕКОТОРЫХ ВИДОВ РОДА FILIPENDULA MILL. НА СОДЕРЖАНИЕ ФЛАВОНОИДОВ И АНТИОКСИДАНТНУЮ АКТИВНОСТЬ
}

\section{(C) Т.М. Шалдаева}

\author{
Центральный сибирский ботанический сад СО РАН, ул. Золотодолинская, \\ 101, Новосибирск, 630090 (Россия), e-mail:tshaldaeva@yandex.ru
}

Изучено содержание флавоноидов и суммарная антиоксидантная активность 12 образцов листьев и цветков трех видов рода Filipendula:F. ulmaria, F. vulgaris, F. stepposa. Методом ВЭЖХ определен состав флавоноидов в листьях. Установлено, что все изученные виды лабазника содержат значительное количество флавоноидов: в листьях F. ulmaria - до $3,1 \%$, в цветках - до 3,8\%, у F. stepposa - 3,9 и 4,2\% соответственно. Максимальное содержание флавоноидов у $F$. vulgaris - 7,2\% в листьях, 8,0\% в цветках. Методом ВЭЖХ в листьях лабазника идентифицированы кверцетин, кемпферол, гиперозид, авикулярин и эллаговая кислота. Растения лабазника могут быть рекомендованы для использования в качестве сырья содержащего флавоноиды.

Ключевые слова: Filipendula, флавоноиды, антиоксидантная активность, ВЭЖХ.

Работа выполнена при поддержке Интеграџионных проектов СО РАН № 20 и Уральского отделения РАН № 12-C-4-1028.

\section{Ввдение}

Основными критериями для отбора растительного сырья в качестве источника биологически активных соединений являются высокое содержание действующих веществ, отсутствие токсических проявлений при их применении, доступность сырья в природе или несложная технология его культивирования [1]. К таким растениям можно отнести лабазник вязолистный семейства розоцветных (Rosaceae). Ранее было показано, что растения этого вида отличаются высоким содержанием фенольных соединений, состоящих из простых фенолов, фенолкарбоновых кислот, кумаринов, флавоноидов и танинов [2]. Клинические исследования спиртовых, водных и сухих экстрактов выявили наличие мощной противовоспалительной, ранозаживляющей, мочегонной, анестезирующей, противоревматической, антибактериальной, антивирусной, сосудорасширяющей активности, что позволяет его применять в официнальной медицине [3]. Е.Ю. Авдеевой [4] выявлен факт корреляции антиоксидантных свойств лабазника вязолистного с его ноотропной активностью. Установлено, что основной вклад в антиокислительную активность лабазника вносят флавонолгликозиды и фенолокислоты, при этом наибольшей активностью обладают изокверцитрин и филимарин. Поиск новых подходов к выявлению антиоксидантов и определению их активности является весьма актуальной задачей.

Цель данной работы - определить содержание флавоноидов и суммарную антиоксидантную активность (САА) водно-спиртовых извлечений из цветков и листьев дикорастущих видов лабазника F. ulmaria (L.) Maxim, F. vulgaris Moench, F. stepposa Juz. Идентифицировать индивидуальные компоненты в этанольных экстрактах листьев методом ВЭЖХ.

\section{Экспериментальная часть}

Для количественного определения флавоноидов применили спектрофотометрический метод, в котором использована реакция комплексообразования флавоноидов с хлоридом алюминия [5]. При определе-

Шалдаева Татьяна Михайловна - научный сотрудник лаборатории фитохимии, кандидат биологических наук, e-mail: tshaldaeva@yandex.ru нии суммарного содержания антиоксидантов фенольного типа использовали оперативный амперометрический метод [6]. Измерения проводили 
на приборе «Цвет Яуза-01-АА» разработки НПО «Химавтоматика». Для исследования качественного состава флавоноидного комплекса использованы методы бумажной и высокоэффективной жидкостной хроматографии [7]. Исследовали водно-спиртовые экстракты цветков и листьев лабазника обыкновенного, лабазника вязолистного и лабазника степного, собранных в период массового цветения в различных условиях произрастания Новосибирской области и Алтая.

Содержание флавоноидов в растительном сырье является важнейшим показателем его биологической ценности. На содержание флавоноидов и суммарной антиоксидантной активности было проанализировано 12 образцов цветков и листьев лабазника. Наибольшее количество флавоноидов обнаружено в образцах F. vulgaris - от 3,7 до $8,0 \%$ в цветках и от 3,2 до 7,2\% в листьях (рис. 1).

В образцах $F$. ulmaria содержание флавоноидов варьировало в цветках от 3,1 до 3,8\% и в листьях от 2,6 до 3,1\%; в цветках F. stepposa - от 1,7 до 4,2\%, в листьях - от 1,4 до 3,9\%. Растения всех исследованных видов лабазника могут быть рекомендованы для использования в качестве сырья, содержащего флавоноиды. Проведенный нами анализ на суммарную антиоксидантную активность растений рода Filipendula выявил, что эти показатели значительно варьируют, ту или иную антиоксидантную активность проявляют экстракты всех изученных видов (рис. 2).

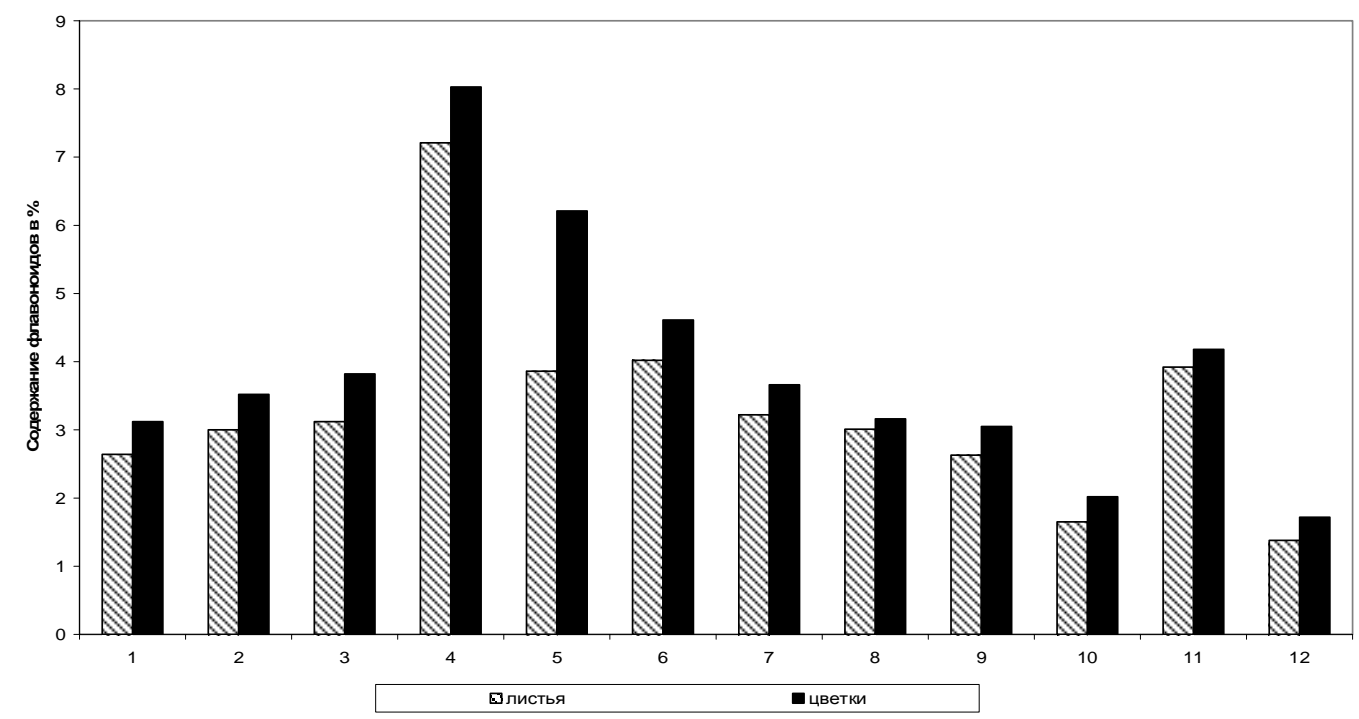

Рис. 1. Суммарное содержание флавоноидов в листьях и цветках трех видов лабазника. 1-3 - Filipendula ulmaria, 4-8-F. vulgaris, 9-12-F. stepposa

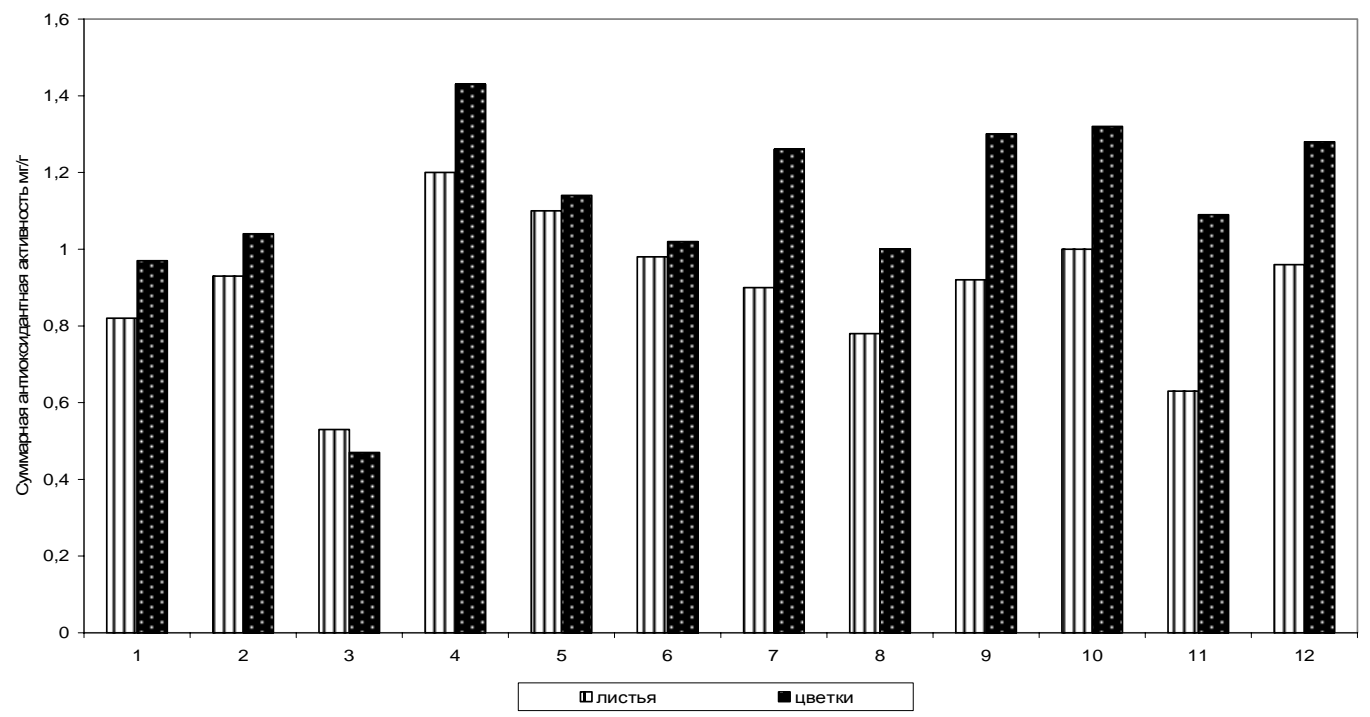

Рис. 2. Суммарная антиоксидантная активность листьев и цветков видов лабазника. 1-3 - F. ulmaria, 4-8 F. vulgaris, 9-12-F. stepposa 
Самые высокие показатели антиоксидантной активности водно-спиртовых экстрактов цветков и листьев у лабазника обыкновенного - от 1,0 до 1,4 мг/г в цветках и от 0,9 до 1,2 мг/г в листьях. У остальных видов антиоксидантная активность ниже - у F. stepposa - 1,0-1,3 мг/Г в цветках и 0,6-1,0 мг/Г в листьях, у F. ulmaria - 0,5-1,0 мг/г в цветках и 0,5-0,9 мг/г в листьях. Из исследованных образцов лабазника выделяется F. vulgaris из Купинского района (проба №4) с максимальным содержанием флавоноидов и высокой антиоксидантной активностью.

Методом ВЭЖХ в этанольных экстрактах листьев лабазников обнаружено 10-13 веществ, большая часть их, судя по спектрам, относится к фенольным соединениям. Среди них идентифицированы флавонолы - кверцетин, кемпферол, гиперозид, рутин, авикулярин и эллаговая кислота (рис. 3). В экстрактах листьев всех видов присутствуют - кверцетин, кемпферол, гиперозид, эллаговая кислота. Рутин обнаружен только у F. vulgaris, а авикулярин - у F. vulgaris и F. ulmaria, что согласуется с литературными данными.

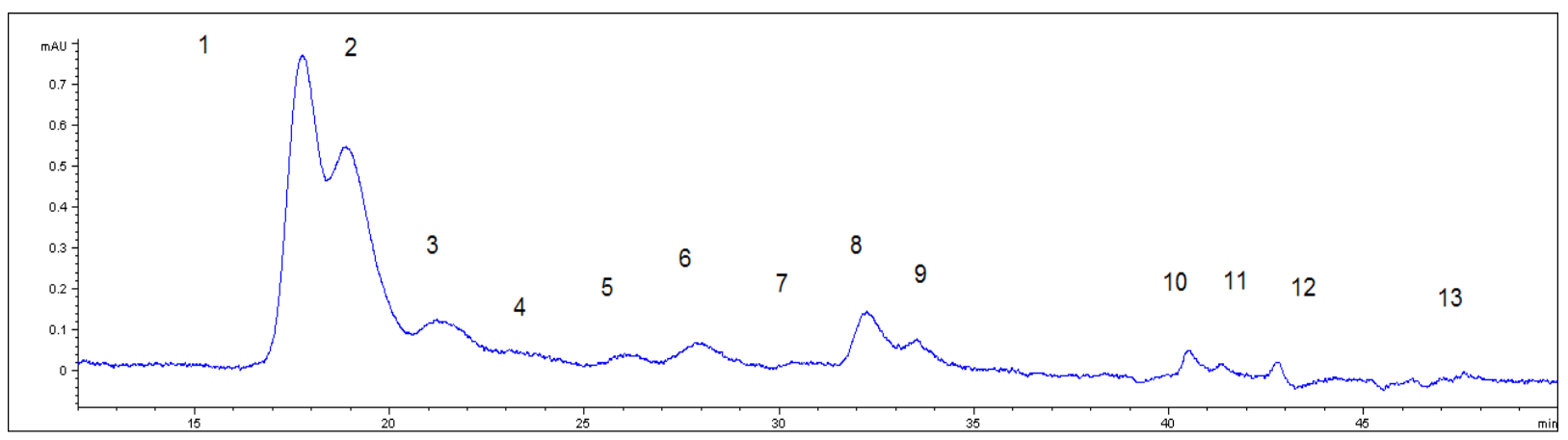

Рис. 3. Хроматограмма этанольного этанольного экстракта листьев Filipendula ulmaria. По оси ординат оптическая плотность. По оси абсцисс - время удерживания, мин. Пики №1 - гиперозид, №6 - авикулярин, №10 - кверцетин, №13 - кемпферол, №3 эллаговая кислота

\section{Выводы}

Все изученные виды лабазника содержат значительное количество флавоноидов: в листьях F. ulmariaдо $3,1 \%$, в цветках - до $3,8 \%$, у F. stepposa - 3,9 и 4,2\% соответственно. Максимальное содержание флавоноидов у F. vulgaris - 7,2\% в листьях, 8,0\% в цветках. Следовательно, растения лабазника могут быть рекомендованы для использования в качестве сырья, содержащего флавоноиды. Методом ВЭЖХ в листьях лабазника идентифицированы кверцетин, кемпферол, гиперозид, авикулярин и эллаговая кислота.

\section{Сиисок литературы}

1. Башилов А.В., Решетников В.Н. Биологическая и фармакологическая характеристика лабазника вязолистного (Filipendula ulmaria (L.) Maxim.) и лабазника шестилепестного (Filipendula hexapetala Gilib.), обладающих выраженным противовоспалительным действием // Нарочанские чтения: материалы Международной научнопрактической конференции. Минск, 2006. С. 4-12.

2. Краснов Е.А., Авдеева Е.Ю. Химический состав растений рода Filipendula // Химия растительного сырья. 2012. №4. С. 5-12.

3. Шилова И.В., Семенов А.А., Суслов Н.И., Короткова Е.И., Вторушина А.Н., Белякова В.В. Химический состав и биологическая активность фракции экстракта лабазника вязолистного // Химико-фармацевтический журнал. 2009. Т. 43, №4. С. 7-11.

4. Авдеева Е.Ю. Исследование лабазника вязолистного как источника эффективного ноотропного средства : автореф. дис. ... канд. фарм. наук. Пермь, 2004. 24 с.

5. Беликов В.В., Шрайбер М.С. Методы анализа флавоноидных соединений // Фармация. 1970. Т. 19, №1. С. 66-72.

6. Яшин А.Я., Яшин Я.И., Черноусова Н.И., Пахомов В.П. Новый прибор для определения природных антиоксидантов. М., 2005. 100 с.

7. Храмова Е.П., Комаревцева Е.К. Изменчивость флавоноидного состава листьев Potentilla fructicosa (Rosacea) разных возрастных состояний в условиях Горного Алтая // Растительные ресурсы. 2008. Т. 44, вып. 3. C. 96-102. 
Shaldaeva T.M. A STUDY OF SOME SPECIES OF FILIPENDULA MILL. ON THE CONTENT OF FLAVONOIDS AND ANTIOXIDANT ACTIVITY

Central Siberian Botanical Garden SB RAS, Zolotodolinskaja st., 101, Novosibirsk, 630090 (Russia), e-mail:tshaldaeva@yandex.ru

The content of total flavonoids and antioxidant activity of 12 samples of leaves and flowers of three species of the genus Filipendula: F. ulmaria, F. vulgaris, F. stepposa. HPLC to determine the composition of flavonoids in the leaves. It found that all studied species Filipendula contain significant amounts of flavonoids: the leaves F. ulmaria - up to 3,1\%, in the flowers - up to 3,8\%, in F. stepposa-3,9 and 4,2\%, respectively. The maximum content of flavonoids from $F$. vulgaris $-7,2 \%$ in the leaves, $8,0 \%$ in the flowers. HPLC identified in the leaves of meadowsweet quercetin, kaempferol, hyperoside, avikulyarin and ellagic acid. Plants Filipendula can be recommended for use as feedstock containing flavonoids.

Keywords: Filipendula, flavonoids, antioxidant activity, HPLC.

\section{References}

1. Bashilov A.V., Reshetnikov V.N. Materialy mezhdunarodnoj nauchno-prakticheskoj konferencii (Narochanskie chtenija) [Proceedings of the international scientific-practical conference (Naroch reading)]. Minsk, 2006, pp. 4-12. (in Russ.).

2. Krasnov E.A., Avdeeva E.Ju. Himija rastitel'nogo syr'ja, 2012, no. 4, pp. 5-12. (in Russ.).

3. Shilova I.V., Semenov A.A., Suslov N.I., Korotkova E.I., Vtorushina A.N., Beljakova V.V. Himiko-farmacevticheskij zhurnal, 2009, vol. 43, no. 4, pp. 7-11. (in Russ.).

4. Avdeeva E.Ju. Issledovanie labaznika vjazolistnogo kak istochnika jeffektivnogo nootropnogo sredstva: avtoref. dis. ... kand. farm. nauk. [Research meadowsweet as a source of effective nootropic agents: dissertation of the candidate of pharmaceutical sciences]. Perm, 2004, 24 p. (in Russ.).

5. Belikov V.V, Shrajber M.S. Farmacija, 1970, vol. 19, no. 1, pp. 66-72. (in Russ.).

6. Jashin A.Ja., Jashin Ja.I., Chernousova N.I., Pahomov V.P. Novyj pribor dlja opredelenija prirodnyh antioksidantov. [New device for determining the natural antioxidants]. Moscow, 2005, 100 p. (in Russ.).

7. Hramova E.P., Komarevceva E.K. Rastitel'nye resursy, 2008, vol. 44, no. 3, pp. 96-102. (in Russ.).

Received February 24, 2014 